\title{
Efectos de los cambios en el programa Procampo en la economía rural del sureste mexicano
}

\section{Effects of the changes in Procampo program on the rural economy of southeastern Mexico}

\author{
Jesús Arellano-GonZÁlez*
}

\begin{abstract}
This research analyses the effects on the rural economy of the mexican southeastern rural region that result from changes in the implementation of the Program of Direct Supports for the Countryside (Programa de Apoyos Directos al Campo, Procampo). The analysis is based on a Multipliers Model applied to a Social Accounting Matrix constructed with data from the National Survey on Rural Households in Mexico. The results show that any modification to Procampo affects all the economic activities in the region and that the differentiated payment scheme per hectare applicable since 2009 has a more progressive effect than the previous single payment per hectare applied until 2008.
\end{abstract}

Keywords: agricultural policy, Social Accounting Matrix, multipliers model.

\section{Resumen}

Esta investigación examina los efectos derivados de cambios en la implementación del Programa de Apoyos Directos al Campo (Procampo) en la economía rural del sureste mexicano. El análisis se basa en la aplicación del modelo de multiplicadores a una Matriz de Contabilidad Social construida con datos de la Encuesta Nacional a Hogares Rurales de México. Los resultados muestran que cualquier modificación del Procampo afecta a todas las actividades económicas de la región y que el esquema de pagos diferenciados, vigente desde el 2009, tiene un efecto más progresivo que el esquema de pago único por hectárea aplicado hasta el 2008.

Palabras clave: política agrícola, Matriz de Contabilidad Social, modelo de multiplicadores.

* El Colegio de México, A. c. Correo-e: jagonzalez@colmex.mx 


\section{Introducción}

El planteamiento de las políticas públicas dirigidas al sector rural mexicano exige un claro entendimiento del funcionamiento de la economía rural y de los posibles impactos que tales políticas puedan generar una vez implementadas.

El agro mexicano se caracteriza por su gran heterogeneidad; en el país conviven dos categorías de productores, por un lado, un gran número de agricultores con pequeñas porciones de terreno que generalmente producen para su propio consumo y con una participación marginal en el mercado agropecuario, por otra parte, existe un pequeño número de agricultores propietarios de medianos y grandes predios con tierras de riego o de buen temporal, con acceso al crédito y a la tecnología, y cuyas decisiones de producción responden a las necesidades de la demanda en los mercados nacionales e internacionales.

Estas diferencias están presentes también en el plano de las regiones rurales de México. Los estados del sureste mexicano concentran la mayor cantidad de población rural e indígena y están, al mismo tiempo, asociados a los mayores niveles de pobreza y marginación. En el plano agropecuario, el tamaño promedio del predio agrícola en dichos estados no supera las cinco hectáreas (ha), los niveles de mecanización son muy bajos y la producción es principalmente de temporal. Contrario a lo anterior, en las regiones del norte se concentra la mayor parte de la agricultura empresarial del país (Sagarpa, 2006).

Dadas estas marcadas diferencias regionales, el efecto de las políticas enfocadas al sector pueden diferir dependiendo del contexto en que sean implementadas.

El principal objetivo de esta investigacion es contribuir al estudio de los efectos directos e indirectos de las políticas públicas en la economía del sector rural mexicano. En particular, este trabajo se enfoca en el programa Procampo, el programa de transferencias directas a los productores agrícolas de mayor importancia en el presupuesto federal. Asimismo, el análisis se dirige a la región rural del sureste mexicano, la cual tiene el menor grado de desarrollo agrícola del país.

El análisis se basa en la construcción de una Matriz de Contabilidad Social (MCs) y en la aplicación del modelo de multiplicadores a la estructura económica reflejada en ella. La MCs ha sido el punto de partida para el planteamiento de distintos estudios enfocados a la evaluación de los efectos de diversos cambios exógenos en la estructura económica original. Su principal aplicación se ha dado en el desarrollo de los modelos multisectoriales de multiplicadores (Khan y Thorbecke, 1989; Adelman et al., 1988; Adelman y Taylor, 1990; Subramanian y Sadoulet, 1990; Lewis 
y Thorbecke, 1992; Parikh y Thorbecke, 1996) y de equilibrio general (Adelman y Taylor, 1991; Taylor y Yúnez-Naude, 2002; Holden et al., 1999; Taylor et al. 2005). En particular, este análisis evaluará los efectos directos e indirectos del cambio en la implementación del programa Procampo, en la economía rural del sureste mexicano al pasar del esquema de pago único por hectárea vigente, hasta el 2008, al esquema de pago por hectárea diferenciado en función al tamaño del predio vigente desde el 2009.

\section{Metodología}

\subsection{La Matriz de Contabilidad Social (MCS)}

Una MCs es un sistema de contabilidad de doble entrada que recoge todas las transacciones y transferencias que se realizan entre los distintos agentes de un sistema económico en un periodo determinado de tiempo, generalmente un año. En una Mcs desagregada a nivel regional se representan todos los flujos monetarios del sistema económico en un área geográfica determinada.

Con el uso de los datos adecuados, una MCs regional puede reconocer e incorporar al análisis económico el elevado grado de complejidad que existe en las transacciones de los agentes económicos que en ella participan. Su construcción y estudio puede ser de gran interés y utilidad, sobre todo en países en los que las estructuras socioeconómicas de las regiones son muy diferentes entre sí y, por tanto, también lo serán los efectos directos e indirectos de determinados cambios exógenos. En la MCs regional es posible incorporar rasgos muy característicos de la economía rural como son el autoconsumo, las transferencias en especie, el trabajo familiar y la marcada diversificación de las fuentes de ingreso de los hogares rurales.

El esquema básico de una MCs desagregada a nivel regional se muestra en el cuadro 1; las cuentas se clasifican por lo general en cinco grandes grupos: actividades, factores, instituciones (familias y gobierno), capital y sector externo. En la MCs cada sector/agente está representado por una fila y una columna. Por convención, las columnas recogen los gastos y las filas los ingresos. En notación matricial, si la MCs es la matriz X, cada elemento $\mathrm{x}_{\mathrm{ij}}$ es el ingreso del sector/agente $\mathrm{i}$ que proviene del sector/ agente $j$.

A partir de este esquema se puede establecer el flujo monetario de la economía regional. Las actividades productivas reciben sus ingresos por las ventas a otros sectores productivos (matriz insumo-producto), a las instituciones (hogares y gobierno) y a los sectores externos (exportaciones). 


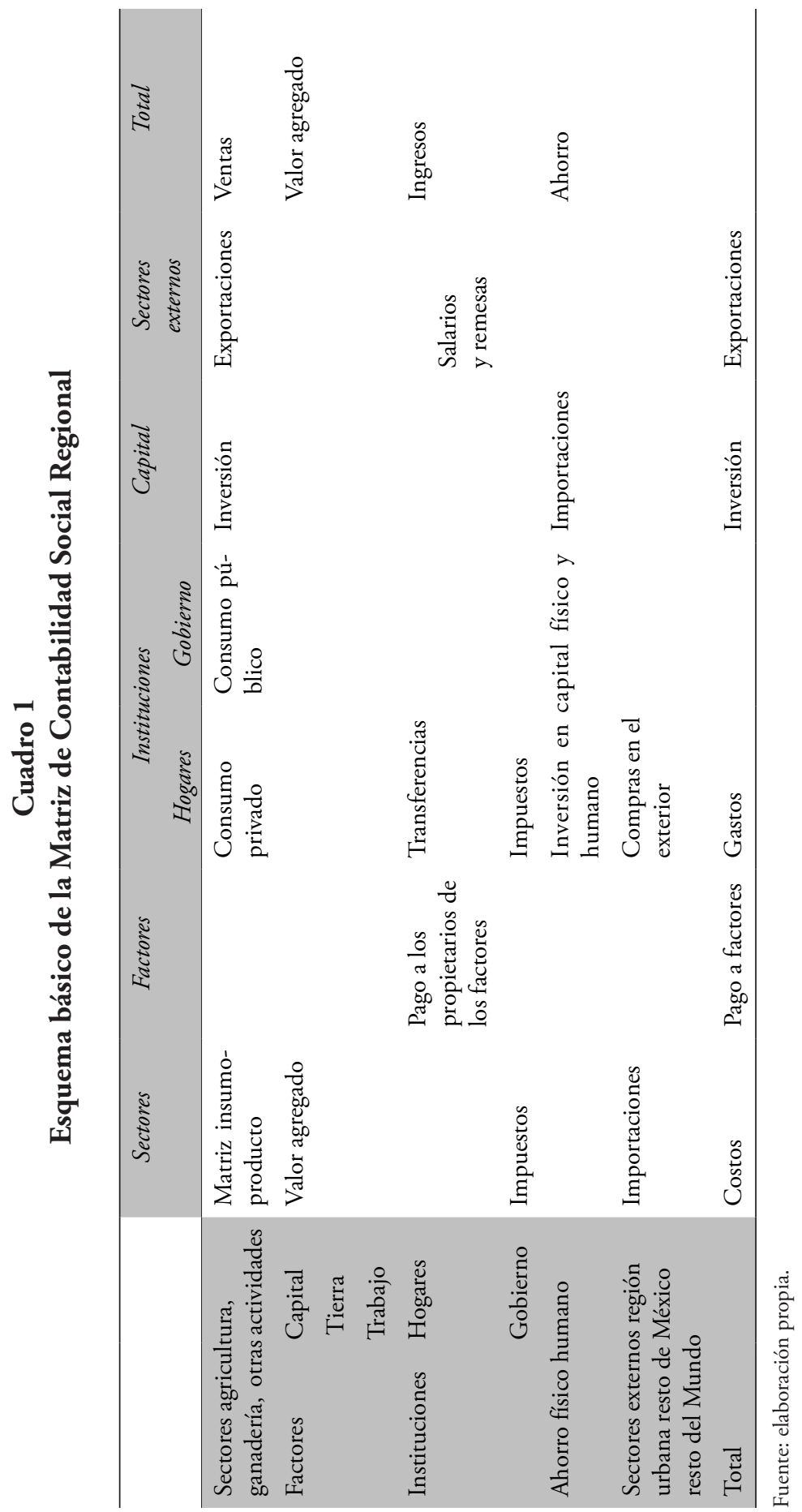


Estos ingresos son canalizados al gasto en productos de otras actividades (insumos intermedios), pago a factores, pago de impuestos y compras en los sectores externos (importaciones). A su vez los hogares, cuyos ingresos están dados por el pago a los factores que poseen, los salarios, las remesas y las transferencias, gastan en consumo directo de los sectores productivos, impuestos, compras al exterior e inversión en capital físico o humano (ahorro). El gobierno obtiene sus ingresos por el cobro de impuestos directos a los hogares y a las actividades de producción y gasta en transferencias a los primeros y en consumo público de los sectores productivos.

Los sectores externos obtienen ingresos de la región por las importaciones de las actividades productivas y las compras de bienes y servicios realizadas por los hogares, y gastan en la región adquiriendo mercancías y servicios (exportaciones), así como en salarios pagados a los hogares y remesas enviadas por el resto del país u otras partes del mundo.

Las cuentas de la mcs deben estar balanceadas: los costos de producción de los sectores productivos deben ser iguales a su ventas, el pago total de los factores a sus propietarios debe ser igual al valor agregado, los gastos de las instituciones deben ser iguales a sus ingresos, la inversión debe ser equivalente al ahorro y las importaciones de los sectores externos iguales a las exportaciones de la región. ${ }^{1}$

\subsection{La Encuesta Nacional a Hogares Rurales de México}

La mayor limitante para la construcción una MCs desagregada a nivel regional y rural es la falta de una base de datos que capture la complejidad de las interacciones de los agentes económicos en la economía rural, pues se requiere información suficientemente detallada para clasificar por origen y destino sus ingresos y gastos.

La Encuesta Nacional a Hogares Rurales de México (Enhrum, 2003) es un proyecto coordinado por el Programa de Estudios del Cambio Económico y la Sustentabilidad del Agro Mexicano (Precesam) del Centro de Estudios Económicos de El Colegio de México y constituye la única fuente de información disponible en México que representa, con tal nivel de detalle, a la economía rural.

La Enhrum contiene información de los hogares rurales para el año 2002. Su cobertura geográfica es nacional para poblaciones rurales de 500

\footnotetext{
${ }^{1}$ La demanda de los bienes y servicios provistos por el exterior puede ser mayor que la oferta de bienes y servicios que el sector rural hace a los sectores externos. Para efectos de balance, es comúnmente asumido que el déficit o superávit existente puede ser atribuido a otra de las cuentas externas. Los desbalances existentes pueden ser corregidos aplicando un método matemático que distribuye iterativamente las diferencias entre las distintas cuentas hasta que los totales se igualan.
} 
a 2,499 habitantes. La encuesta se levantó en 80 localidades rurales de 14 estados de la república. El total de viviendas fue de 1,765, muestra representativa a nivel nacional y regional.

El diseño original de la Enhrum facilita la aplicación de los modelos multisectoriales al caso mexicano. Además, incluye datos sociodemográficos y económicos de los hogares y sus miembros, la Enhrum incluye información detallada sobre las actividades productivas de los hogares, el origen y destino de las transacciones monetarias en toda la economía rural y una valoración del trabajo familiar y la producción para autoconsumo.

El tamaño de la muestra correspondiente a la región sureste consiste en información para 367 hogares, con representatividad para 1.3 millones de ellos a nivel nacional. Cabe aclarar que la Sagarpa (2011) define como región agroalimentaria sur-sureste a los estados de Campeche, Chiapas, Quintana Roo, Tabasco, Oaxaca, Veracruz y Yucatán, mientras que la muestra de la Enhrum solo incluye a los últimos tres.

Los datos de la muestra de la Enhrum se utilizaron para construir la MCs del sureste mexicano de acuerdo a los procedimientos generales indicados en Yúnez-Naude y Taylor (1999). La MCs construida para el sector rural del sureste mexicano se puede visualizar en el anexo 1, en el que se definieron cinco actividades productivas: cultivos básicos (maíz y fríjol), otros cultivos (resto de los cultivos), ganadería, recursos naturales y pesca, comercio y servicios. Estas actividades generan valor agregado a través del uso de cuatro factores de producción: tierra, capital, trabajo asalariado y trabajo familiar. El valor del trabajo familiar resulta de calcular el ingreso neto de los hogares por realizar alguna actividad productiva.

Los hogares fueron clasificados en productores y no productores. Los primeros constituyen los que, con tierra propia o arrendada, producen bienes agropecuarios. Los segundos son aquéllos cuyos ingresos son obtenidos enteramente de otras actividades. De los hogares rurales del sureste mexicano $71 \%$ fueron clasificados como productores.

A su vez, estos hogares fueron clasificados en propietarios y no propietarios; los primeros poseen dominio pleno sobre las parcelas que utilizan, los segundos utilizan parcelas rentadas, prestadas o sujetas a determinados contratos de aparcería. De los hogares productores de la región sureste $80 \%$ fueron clasificados como propietarios. Finalmente, hogares productores propietarios y no propietarios fueron clasificados de acuerdo a la extensión de las parcelas que cultivan.

Hay cuentas que capturan la interacción entre el gobierno y la economía rural: las transferencias públicas hacia los hogares (Procampo, Oportunidades) y el pago de los hogares por impuestos y por la provisión de servicios públicos (luz y agua). Existe una cuenta adicional que captura 
las interacciones económicas entre otras instituciones (organizaciones sociales o privadas) y los hogares a través de donaciones o transferencias.

La cuenta de capital se subdivide en físico (recursos monetarios necesarios para financiar la inversión en capital fijo) y humano (gasto en educación de los miembros de hogar) y la vinculación de la economía rural con el sector externo es capturada a través de tres cuentas: región urbana (zonas urbanas en la región sureste), resto de México (resto de los estados de la república) y resto del mundo (principalmente Estados Unidos).

En el análisis se asume que la estructura económica reflejada por la MCs con datos de la Enhrum para el 2002 se mantiene en el 2009, año en el que sucede el cambio en la implementación del programa Procampo. Este supuesto es necesario ya que, en fechas más cercanas al cambio en la política, no existen otros datos que permitan desglosar la economía rural al nivel tan detallado que permite la Enhrum y que se requiere para la construcción de una MCs.

\subsection{El modelo de multiplicadores aplicado a la MCS}

El modelo lineal de multiplicadores permite captar los efectos desagregados que se generan en la actividad económica de los distintos agentes a partir del flujo circular de la renta establecido en una MCs. Su estimación es útil para explorar el impacto que tienen diversos cambios exógenos sobre la economía en estudio.

\section{Cuadro 2 \\ Representación esquemática de cuentas endógenas y exógenas de la MCS}

\begin{tabular}{|c|c|c|c|c|c|c|}
\hline & & \multicolumn{5}{|c|}{ Gastos } \\
\hline & & Endógenas & Subtotal & Exógenas & Subtotal & Totales \\
\hline \multirow{2}{*}{ Ingresos } & Endógenas & $\begin{array}{l}\text { Transacciones } \\
\text { entre cuentas } \\
\text { endógenas (E) }\end{array}$ & $\mathrm{n}$ & $\begin{array}{l}\text { Pagos de } \\
\text { cuentas } \\
\text { exógenas a } \\
\text { endógenas (X) }\end{array}$ & $\mathrm{x}$ & Ye \\
\hline & Exógenas & $\begin{array}{l}\text { Pagos de } \\
\text { cuentas } \\
\text { endógenas a } \\
\text { exógenas (L) }\end{array}$ & 1 & $\begin{array}{l}\text { Transacciones } \\
\text { entre cuentas } \\
\text { exógenas }(\mathrm{R})\end{array}$ & $\mathrm{r}$ & Yx \\
\hline Totales & & Ye & & $Y x$ & & \\
\hline
\end{tabular}

Fuente: elaboración propia. 
El primer paso para la construcción del modelo de multiplicadores es la clasificación de las cuentas de la MCs en dos bloques: cuentas endógenas y cuentas exógenas ${ }^{2}$ (cuadro 2).

Donde Ye y Yx son los ingresos totales recibidos por las cuentas endógenas y exógenas respectivamente. Si tenemos $\mathrm{n}$ cuentas endógenas y z cuentas exógenas es verdad que:

$$
\begin{aligned}
& \mathrm{Ye}_{(\mathrm{nx} 1)}=\mathrm{n}_{(\mathrm{nx} 1)}+\mathrm{x}_{(\mathrm{nx1})} \\
& \mathrm{Yx}_{(\mathrm{zx} 1)}=\mathrm{l}_{(\mathrm{zx} 1)}+\mathrm{r}_{(\mathrm{zx} 1)}
\end{aligned}
$$

El vector $\mathrm{x}_{(\mathrm{nxl})}$ resume los pagos de las cuentas exógenas a las cuentas endógenas. Dividiendo cada celda de la matriz por el total de su columna respectiva se genera la matriz de propensiones medias al gasto $S_{(\mathrm{n}+\mathrm{z}) \times(\mathrm{n}+\mathrm{z})}$. La eliminación de las filas y columnas de las cuentas exógenas de la matriz $S$ origina la matriz de propensiones medias al gasto entre cuentas endógenas $\mathrm{A}_{\mathrm{E}(\mathrm{nxn})}$. Como $\mathrm{A}_{\mathrm{E}(\mathrm{nxn})}$ contiene las propensiones medias al gasto entre cuentas endógenas es cierto que:

$$
\mathrm{n}_{(\mathrm{n} \times 1)}=\mathrm{A}_{\mathrm{E}(\mathrm{n} \times \mathrm{n})} * \mathrm{Ye}_{(\mathrm{nx} 1)}
$$

Al sustituir esta expresión en (1) y resolver para Ye tenemos:

$$
\mathrm{Ye}=\mathrm{A}_{\mathrm{E}}{ }^{*} \mathrm{Ye}+\mathrm{x}=\left(\mathrm{I}-\mathrm{A}_{\mathrm{E}}\right)^{-1} \mathrm{x}=\mathrm{M}_{(\mathrm{nxn})}{ }^{*} \mathrm{x}
$$

Donde $\mathrm{M}$ es la matriz de multiplicadores. La ecuación 4 expresa el producto e ingreso total de equilibrio consistente con cualquier conjunto de inyecciones x. En otras palabras, esta ecuación expresa al ingreso de las cuentas endógenas como una función lineal del nivel de gasto de las cuentas exógenas en las cuentas endógenas. A través de su estimación es posible evaluar el efecto de cualquier cambio exógeno en el vector x en los niveles de ingreso de las cuentas endógenas, Ye.

En la MCs construida para los hogares rurales del sureste mexicano se consideraron como cuentas endógenas las referentes a las cinco actividades productivas y a los siete grupos de hogares definidos. Se consideraron como cuentas exógenas las relacionadas con el gobierno (Procampo, Oportunidades, otras transferencias públicas), con el capital (ahorro e inversión) y con los sectores externos (región urbana, resto del país y resto del mundo).

Los datos correspondientes a las transferencias del gobierno a los hogares rurales del sureste a través del programa Procampo están contenidos en el vector $\mathrm{x}$ de transferencias exógenas. modelo.

2 Véase Pyatt y Round, 1979; Defourny y Thorbecke, 1984 o Round, 2003 para detalles del 
Es necesario aclarar que los resultados obtenidos en este análisis, tras la aplicación del modelo de multiplicadores, únicamente se refieren a los que se obtienen ante cambios exógenos en la política de implementación del programa Procampo; se mantienen constantes otras políticas públicas o factores exógenos que pudieran incidir en los niveles de ingreso de los hogares y de las actividades productivas de la región (por ejemplo, las transferencias de otros programas públicos dirigidos al sector agropecuario o las remesas percibidas por los hogares rurales).

\section{Resultados}

\subsection{Estructura económica del sector rural del sureste mexicano de acuerdo a la MCS}

\subsubsection{Estructura de la producción rural}

El cuadro 3 muestra el valor de la producción regional así como el valor agregado que se genera por las actividades productivas definidas en la MCS para el sector rural del sureste mexicano. Del valor total de la producción, $30.3 \%$ proviene del sector agropecuario (agricultura y ganadería). El componente de este sector que más contribuye a la generación de valor agregado es el de cultivos básicos (18.8\%), seguido de otros cultivos (6.2\%). La actividad de recursos naturales y pesca contribuye con $23.0 \%$ del valor de la producción y $24.3 \%$ del valor agregado. El sector comercio y servicios representa $43.7 \%$ del valor de la producción y $45.7 \%$ del valor agregado total, principalmente por la elevada retribución al trabajo familiar en esta actividad.

\section{Cuadro 3}

Valor y distribución de la producción del sector rural del sureste mexicano (millones de pesos)

\begin{tabular}{lrrrr}
\hline \multirow{2}{*}{ Actividad productiva } & \multicolumn{2}{c}{ Valor de la producción } & \multicolumn{2}{c}{ Valor agregado } \\
& \multicolumn{1}{c}{ Monto } & \multicolumn{1}{c}{$\%$} & \multicolumn{1}{c}{ Monto } & \multicolumn{1}{c}{$\%$} \\
\hline Cultivos básicos & $4,218.4$ & 15.4 & $3,249.2$ & 18.8 \\
Otros cultivos & $1,488.3$ & 5.4 & $1,077.8$ & 6.2 \\
Ganadería & $2,604.7$ & 9.5 & 770.1 & 4.5 \\
Recursos naturales y pesca & $6,282.8$ & 23.0 & $4,195.7$ & 24.3 \\
Comercio y servicios & $11,938.2$ & 43.7 & $7,898.8$ & 45.7 \\
Otros & 784.4 & 2.9 & 107.1 & 0.6 \\
Total & $27,316.9$ & 100.0 & $17,298.6$ & 100.0 \\
\hline
\end{tabular}

Fuente: Enhrum, 2003. 


\subsubsection{Composición del ingreso de los hogares rurales}

En promedio, en el 2002, un hogar rural del sureste mexicano obtuvo un ingreso anual de 22,851 pesos o el equivalente a 1,900 pesos mensuales. En términos per cápita, cada miembro del hogar obtuvo un ingreso promedio de 4,786 pesos anuales o el equivalente a 400 pesos mensuales. Los hogares no productores ostentan los mayores niveles de ingreso por hogar y por persona de todo el sector rural del sureste mexicano. Su nivel de ingreso per cápita es $90 \%$ mayor que el de los hogares productores propietarios de menos de dos hectáreas. Este grupo de hogares presenta los niveles más bajos de ingreso por hogar y por persona (cuadro 4).

El nivel de ingreso crece conforme aumenta el tamaño de la superficie que cultivan los hogares productores propietarios. Sin embargo, vale la pena resaltar que no existe una diferencia significativa entre el nivel de ingreso de los hogares propietarios de menos de dos hectáreas y el nivel de ingreso de los hogares propietarios de entre dos y cinco hectáreas, pues el ingreso per cápita del último grupo de hogares es apenas $2 \%$ mayor que el del primero. En contraste, el nivel de ingreso per cápita de los hogares propietarios de más de cinco hectáreas es $44 \%$ mayor que el de los hogares propietarios de menos de dos hectáreas. En términos de ingreso, los dos grupos de hogares con hasta cinco hectáreas son bastante homogéneos. Sin embargo, el nivel económico de los hogares que cruzan el umbral de las cinco hectáreas es bastante superior.

Las fuentes de ingreso de los hogares rurales del sureste mexicano están muy diversificadas y varían ampliamente entre grupos de hogares. Únicamente $12.2 \%$ de los ingresos netos de los hogares rurales del sureste corresponden a actividades agropecuarias. El peso relativo de este tipo de ingreso aumenta conforme crece el tamaño del predio. En el caso de los hogares productores propietarios de más de cinco hectáreas este porcentaje es de $22.1 \%$.

Puede notarse que los ingresos por la producción de granos básicos representan cierta importancia para todos los grupos de hogares productores (7.8\% de sus ingresos totales). La mayor importancia relativa de los ingresos por la producción de otros cultivos se da en el caso de los hogares productores con más de cinco hectáreas (5.3\%). Los hogares no productores son los que menos dependen del ingreso por actividades agropecuarias con $1.1 \%$ correspondiente enteramente a actividades pecuarias.

El ingreso por actividades no agropecuarias representa $40.8 \%$ de los ingresos netos de los hogares rurales del sureste mexicano. El mayor peso relativo se da para los hogares no productores (55.6\%), aunque es una fuente importante de ingresos para todos los grupos de hogares. 


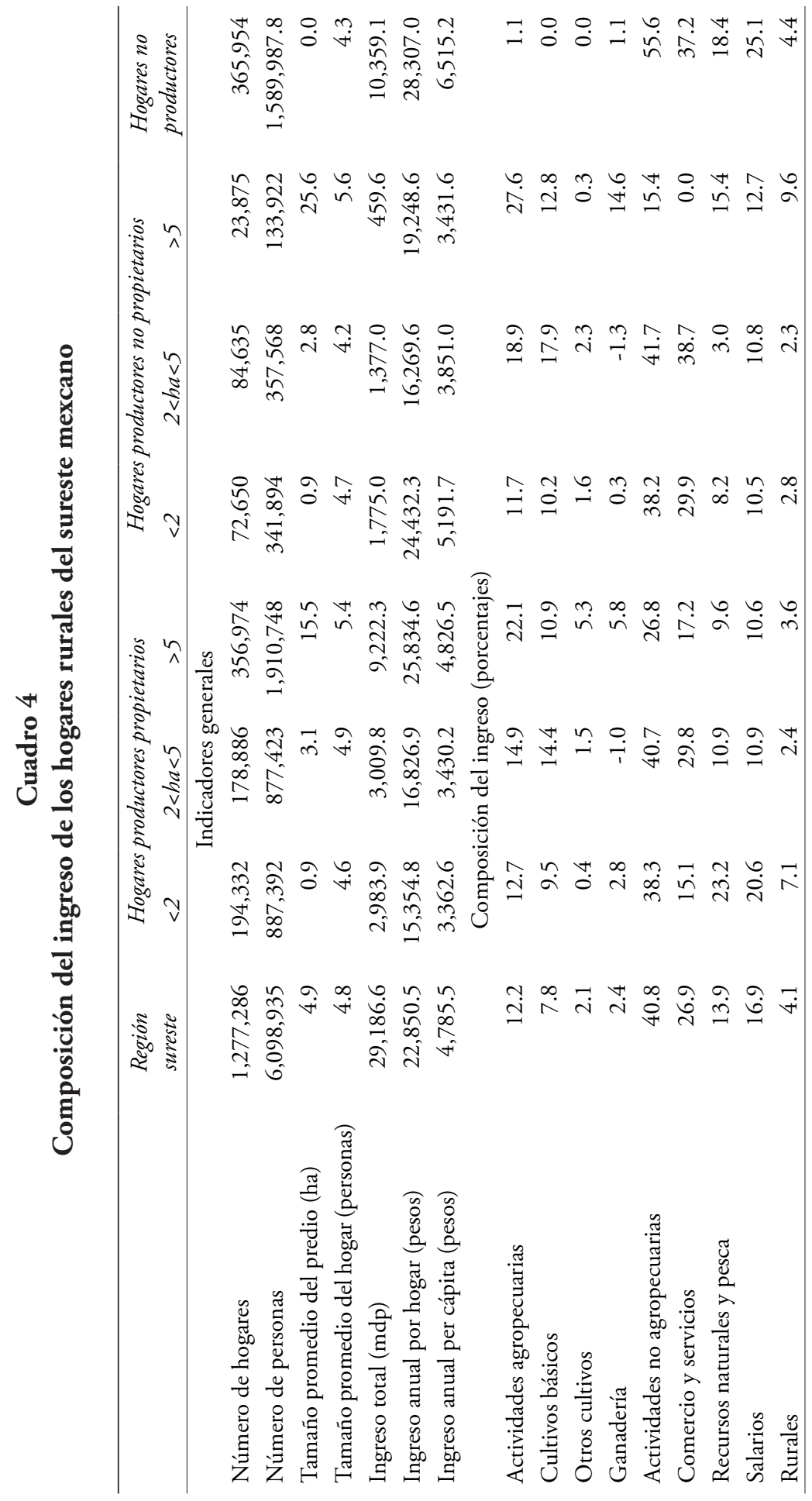




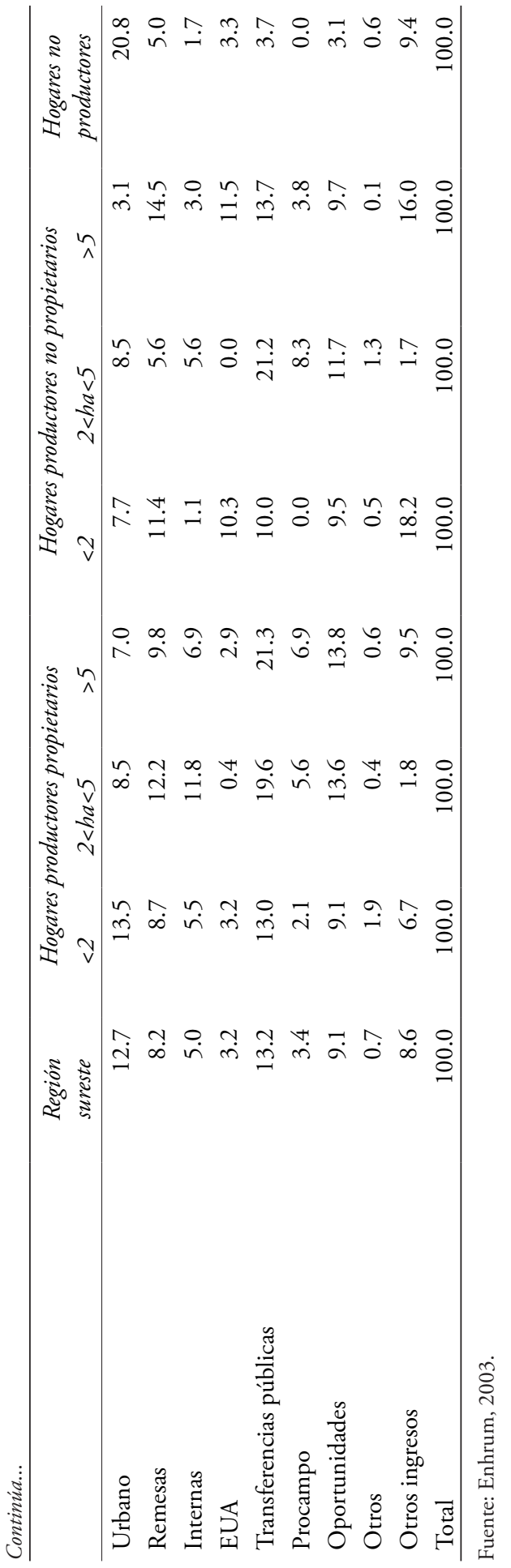


Las retribuciones salariales representan 16.9\% de los ingresos netos de las familias rurales. En su mayoría, los salarios percibidos son generados en las zonas urbanas (12.7\%). Este tipo de ingreso es más importante para los hogares no productores $(25.1 \%)$ y para los pequeños productores propietarios $(20.6 \%)$, lo que denota una elevada participación de estos grupos de hogares en los mercados de trabajo rural y urbano.

Las remesas son también un componente importante en los ingresos de los hogares pues representan $8.2 \%$ y en su mayoría son domésticas (5.0\%).

Las transferencias públicas constituyen 13.2\% de los ingresos de los hogares. El peso relativo de estas transferencias aumenta conforme aumenta la extensión del predio y el grupo de hogares menos favorecido por tales transferencias, que es el de los no productores (3.7\%). El programa Oportunidades tiene el mayor peso relativo entre las transferencias gubernamentales con 9.1\% del ingreso total. El Procampo representa 3.4\% de los ingresos de los hogares de la región sureste. Este peso relativo aumenta con el tamaño del predio hasta llegar a 6.9\% en el caso de los hogares productores propietarios de más de cinco hectáreas.

\subsubsection{Patrones de gasto de los hogares rurales}

Los hogares rurales del sureste mexicano efectúan una gran parte de sus gastos en las zonas urbanas. A nivel regional la dependencia de bienes y servicios de estas zonas es de $28.6 \%$. La proporción es mayor para los hogares no productores no propietarios de entre dos y cinco hectáreas (59.4\%), y es menor para los hogares productores propietarios de más de cinco hectáreas (16.7\%). Este resultado implica que no solamente las actividades productivas vinculan la economía rural con el exterior; la satisfacción de la demanda de bienes y servicios de los hogares rurales depende en gran medida de los mercados urbanos (cuadro 5).

El pago por la provisión de servicios públicos y por impuestos representa únicamente $4.4 \%$ de los gastos totales de los hogares rurales. En lo que respecta al gasto directo en los sectores productivos, en todos los casos, el sector donde más gastan los hogares rurales es el comercio y servicios, pues absorbe $15.6 \%$ de los gastos totales a nivel regional. El consumo de cultivos básicos en casi todos los casos (con la excepción de los hogares no productores) está por encima de $10.0 \%$ de los gastos totales. El consumo directo y el autoconsumo de granos básicos constituyen una parte importante de los patrones de consumo de los hogares del sureste mexicano. 


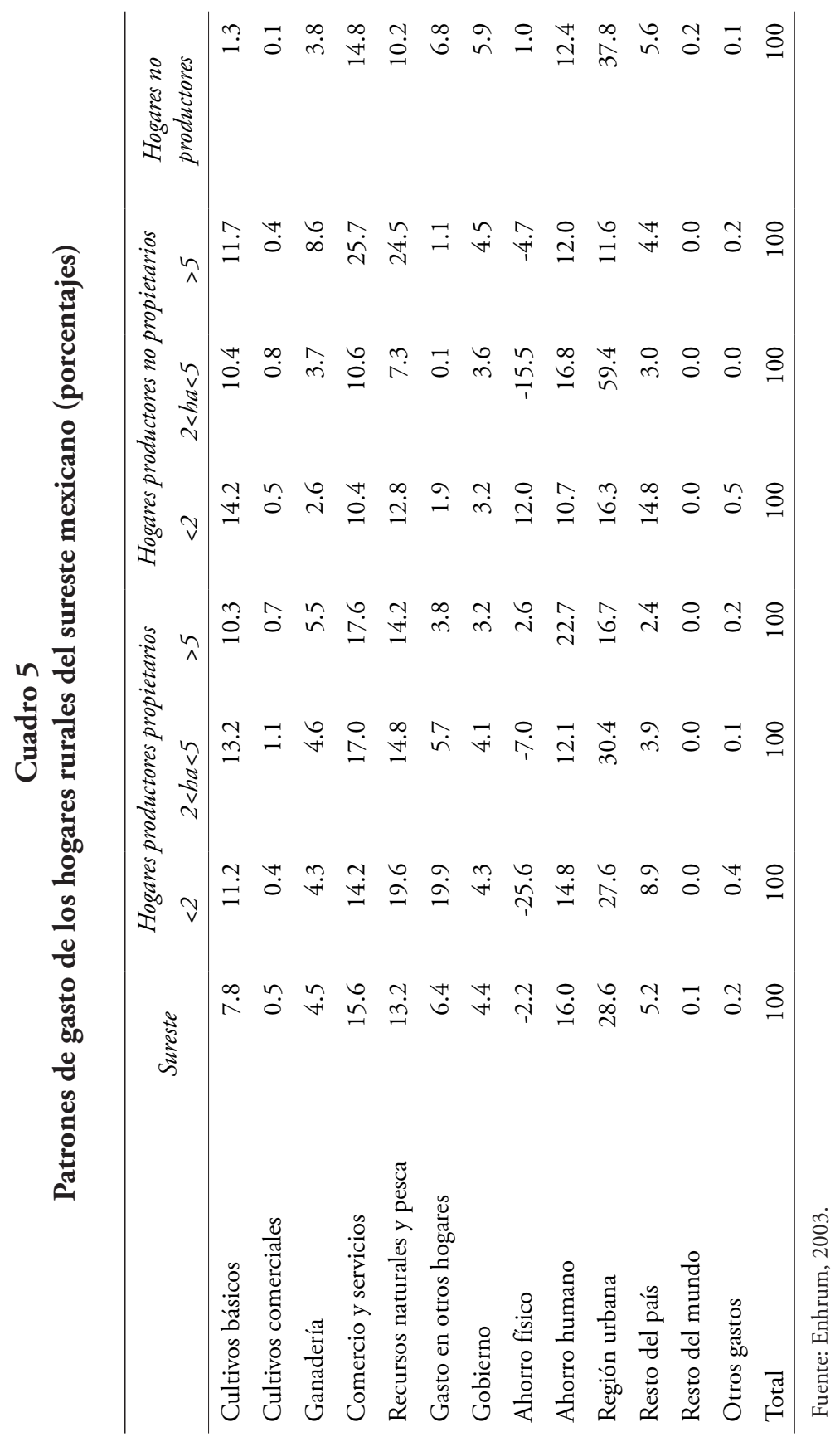


La tasa de ahorro en capital humano es de $16.0 \%$. Esta tasa varía entre grupos de hogares desde $12.4 \%$ para los no productores hasta $22.7 \%$ para los productores propietarios de más de cinco hectáreas (cuadro 5).

En contraste, las tasas de ahorro físico son negativas para la mayoría de los grupos de hogares. El mayor nivel de desahorro lo presentan los pequeños productores propietarios con $25.6 \%$ de sus gastos totales. A nivel regional este desahorro representa $2.2 \%$ de los gastos totales de los hogares. Ello implica que los recursos necesarios para financiar las inversiones en capital fijo provienen necesariamente de préstamos obtenidos por los hogares en instituciones financieras ubicadas principalmente en las zonas urbanas.

\subsection{Análisis de los multiplicadores}

Para el diseño de políticas públicas y la evaluación de ciertos choques económicos exógenos en la economía rural es importante identificar aquellos sectores en los que un cambio exógeno positivo generará efectos multiplicativos significativos en toda la economía rural.

El efecto difusión consiste en el incremento que una unidad monetaria de renta exógena en la cuenta endógena i provoca sobre el ingreso del conjunto de cuentas endógenas. Este efecto se calcula con el total por columna que se obtiene de la matriz de multiplicadores para cada una de las cuentas definidas como endógenas. El efecto difusión es, en palabras sencillas, la intensidad con la que una cuenta endógena en particular gastará su ingreso adicional en el resto de las cuentas endógenas. Las cuentas que presentan los mayores valores crean los efectos de expansión más elevados en el ingreso en el resto de la economía rural.

El efecto absorción consiste en el incremento en el ingreso que una unidad adicional de renta exógena en cada una de las cuentas endógenas provoca en la cuenta endógena i. Este efecto es calculado con el total por fila que se obtiene de la matriz de multiplicadores. En palabras sencillas, el efecto absorción representa la magnitud con la que el conjunto de cuentas endógenas gastarán su ingreso adicional en una cuenta en particular. Las cuentas que presentan los mayores valores absorben de manera más eficiente el efecto de un cambio exógeno en su nivel de ingreso o en el ingreso de otras cuentas.

El cuadro 6 muestra los efectos obtenidos de la matriz de multiplicadores de la región rural del sureste mexicano.

Entre las actividades productivas, el mayor efecto difusión es atribuido al sector de recursos naturales y pesca. Un incremento exógeno de un millón de pesos (mdp en adelante) en el ingreso de esta actividad productiva se traduciría en una expansión de $5.5 \mathrm{mdp}$ a todas las actividades 


\section{Cuadro 6 \\ Efectos difusión y absorción de la MCS del sureste mexicano (millones de pesos)}

\begin{tabular}{lcc}
\hline & Efecto difusión & Efecto absorción \\
\hline Actividades Productivas & & \\
Cultivos básicos & 5.0 & 4.9 \\
Otros cultivos & 4.9 & 1.4 \\
Ganadería & 5.3 & 2.4 \\
Comercio y servicios & 5.0 & 8.5 \\
Recursos naturales y pesca & 5.5 & 6.1 \\
Hogares & & \\
Hogares productores propietarios $<2$ & 4.3 & 3.0 \\
Hogares productores propietarios $2<$ ha $<5$ & 3.8 & 2.8 \\
Hogares productores propietarios $>5$ & 3.6 & 7.2 \\
Hogares productores no ropietarios $<2$ & 3.2 & 2.7 \\
Hogares productores no propietarios $2<\mathrm{ha}<5$ & 2.7 & 1.9 \\
Hogares productores no propietarios $>5$ & 4.7 & 1.9 \\
Hogares no productores & 2.8 & 8.4 \\
\hline
\end{tabular}

Fuente: Cálculos propios a partir de la MCRS del sureste mexicano (Enhrum, 2003).

productivas y hogares de la región. Entre los sectores agropecuarios, la cuenta de otros cultivos presenta el menor efecto difusión. Esto puede deberse, entre otras razones, a la escasa importancia relativa de este sector en la economía rural del sureste mexicano: únicamente 5.4\% del valor de la producción.

Con respecto al efecto absorción, el sector que más se beneficiaría de un incremento exógeno en un millón de pesos, en cada una de las cuentas definidas como endógenas, es el de comercio y servicios, ya que su ingreso final sería 8.5 mdp mayor. El resultado es consistente con los patrones de gasto de los hogares rurales, pues $15.6 \%$ de su gasto total se destina a este sector. Es decir, dadas las propensiones medias a consumir, establecidas en el modelo de multiplicadores, el aumento exógeno en el ingreso de los hogares se traduciría en un mayor gasto en todas las actividades productivas, pero el gasto en ésta actividad aumentaría en una mayor proporción.

Entre los hogares productores propietarios, los de hasta cinco hectáreas presentan un mayor efecto difusión que los hogares con más de cinco hectáreas. En el caso de los hogares propietarios de menos de dos hectáreas, un incremento exógeno de un millón de pesos en el ingreso de este grupo 
de hogares se traduciría en una expansión de $4.3 \mathrm{mdp}$ al resto de hogares y actividades productivas de la región, es éste el mayor efecto difusión entre los hogares productores propietarios.

Este resultado indica que los hogares propietarios de hasta cinco hectáreas, y por ende, los de menor ingreso, gastarán más intensamente su ingreso adicional y por tanto impulsarán más la economía local a través de un mayor consumo.

En contraste, el efecto absorción indica que el grupo de hogares que más se beneficiaría de un aumento exógeno en un millón de pesos en el ingreso de todos los grupos de hogares y todas las actividades productivas serían los productores propietarios de más de cinco hectáreas, pues su ingreso final sería 7.2 mdp mayor. Los hogares productores propietarios de hasta cinco hectáreas no presentan efectos absorción de magnitudes similares. De acuerdo con este resultado, los incrementos exógenos en el nivel de ingreso de los hogares y de las actividades productivas beneficiarán en una menor proporción a los pequeños productores debido, entre otras razones, a que el ingreso adicional en la economía local no será gastado en las actividades productivas ni en los factores de producción en los que los pequeños productores tengan una mayor participación.

\subsection{Cambios en la implementación del Procampo}

El programa Procampo, iniciado en el ciclo agrícola otońo-invierno del año de 1994, meses antes de la entrada en vigor del Tratado de Libre Comercio de América del Norte (TLCAN), tiene como principal objetivo la transferencia de recursos en apoyo a la economía de los productores rurales para compensarlos por las consecuencias derivadas de la apertura comercial. El Procampo también tiene otros objetivos colaterales como mejorar la competitividad, modernizar el sistema de comercialización, la conversión a otros cultivos o actividades más rentables, la regularización de la tenencia de la tierra, la reducción de la emigración rural, entre otros. Hasta la fecha, el logro de estos objetivos no es del todo claro debido a la poca rigurosidad de las evaluaciones oficiales y a la falta de evaluaciones externas independientes y objetivas (Schwentesius-Rindermannet et al., 2007).

El programa Procampo ha tenido poca incidencia en la capitalización y competitividad de las unidades agrícolas del país debido a que se trata de transferencias desligadas de las decisiones de producción de los beneficiarios y asignadas conforme al tamaño de su predio. Su uso como inversión productiva sólo es plausible en el caso de los grandes propietarios (Lorenzen y Matthew, 2012).

A pesar de esta limitante, algunos autores han encontrado evidencia empírica de efectos positivos del Procampo en el mantenimiento de la 
seguridad alimentaria (Ruiz-Arranz et al., 2006), la reducción del flujo migratorio en el medio rural (Cuecuecha y Scott, 2009) y el mantenimiento de la producción de los cultivos básicos en México (Yúnez-Naude y Taylor, 2006; García-Salazar et al., 2011).

En el caso del sureste mexicano, las transferencias de Procampo representan 3.4\% del ingreso de los hogares rurales y su importancia relativa en el ingreso crece conforme aumenta la extensión de terreno sembrada por los hogares rurales, alcanzando $6.9 \%$ en el caso de los hogares propietarios de más de 5 hectáreas. Las transferencias de Procampo se han convertido en una fuente de ingreso relevante para los hogares rurales que las reciben.

La primera columna del cuadro 7 muestra la distribución inicial de las transferencias de Procampo entre los hogares del sureste mexicano. Los hogares productores propietarios de más de cinco hectáreas concentran $64 \%$ de las transferencias totales; la participación del resto de los hogares productores propietarios disminuye conforme disminuye la extensión de sus parcelas.

Hasta el 2008, estas transferencias consistieron en una cuota única por hectárea de 873 pesos otorgada directamente a los productores rurales (DOF, 2002). Tal esquema claramente concentraba la mayoría de los apoyos en los productores con mayores extensiones de terreno. A partir del 2009, las cuotas se diferenciaron otorgándose 1,300 pesos a los productores agrícolas con hasta cinco hectáreas y 963 pesos al resto de los productores (DOF, 2009). Esto representa un aumento en relación con el esquema anterior, de $49 \%$ y $10 \%$ respectivamente. Vale la pena evaluar, en el contexto de la MCs para la región rural del sureste mexicano y del modelo de multiplicadores, el efecto que el cambio exógeno en la implementación del programa tiene en los hogares y en la economía rural.

¿Qué pasaría en la economía rural ante un aumento exógeno en las transferencias de Procampo bajo el anterior esquema de cuota única? La segunda columna del cuadro 7 muestra el monto de las transferencias de Procampo tras aumentarlas exógenamente en $100 \mathrm{mdp}$. Este incremento es asignado a cada grupo de hogares del sureste de México de acuerdo a su participación porcentual en las transferencias del programa. Por ejemplo, los hogares productores propietarios de más de cinco hectáreas reciben $64 \%$ de las transferencias totales de Procampo, por lo que en esta simulación las transferencias a este grupo aumentan en $64 \mathrm{mdp}, 0.69 \%$ de su ingreso total.

La primera columna del cuadro 8 muestra los efectos multiplicadores de esta política ex ante. El incremento exógeno en los ingresos de los hogares origina un aumento en la demanda directa de los sectores productivos debido a un mayor consumo privado. El sector productivo más 
beneficiado sería el de granos básicos con un aumento de 23.3 mdp, $0.55 \%$ de su ingreso total.

En general, el ingreso de todos los sectores productivos aumenta; los sectores productivos, a su vez, incrementan su demanda por insumos intermedios y por factores de producción aumentando aun más, de forma indirecta, los ingresos de los hogares. El aumento inicial de $0.69 \%$ en el ingreso de los hogares productores propietarios se convierte, sumando los efectos multiplicadores, en un aumento final de $0.96 \%$ de su ingreso total.

El efecto final es claramente regresivo para los hogares productores propietarios: a mayor número de hectáreas mayor es el incremento proporcional del ingreso. Es decir, un aumento en las transferencias de Procampo beneficia proporcionalmente más a los grandes productores aun tomando en cuenta los efectos multiplicativos que tendría tal política en la economía rural. Este resultado es consistente con Sadoulet et al. (2001) quienes encuentran el mismo efecto regresivo bajo un enfoque econométrico.

Una vez establecido el carácter regresivo del esquema de cuota única por hectárea del Procampo se evalúa si el esquema de cuota diferenciada, vigente desde 2009, es menos regresivo. Para evaluar lo anterior, las transferencias de Procampo a los hogares (propietarios y no propietarios) del sureste mexicano con hasta cinco hectáreas fueron incrementadas en $49 \%$ y las transferencias a los hogares con más de cinco hectáreas fueron incrementadas en $10 \%$. Estos porcentajes corresponden al incremento porcentual de las cuotas de un esquema a otro. Con esto, las transferencias de Procampo a la región sureste pasarían de 996 mdp a 1,233 mdp y la participación relativa de las transferencias recibidas por los hogares productores propietarios de hasta cinco hectáreas aumentaría, tal como lo muestra la tercera columna del cuadro 7.

Los efectos de este cambio se muestran en la segunda columna del cuadro 8; la producción de los sectores económicos, la generación de valor agregado y el ingreso de todos los grupos de hogares aumentan. El ajuste de la economía rural del sureste a este cambio en la implementación del Procampo ocasiona que el aumento en los ingresos de los hogares productores propietarios de hasta cinco hectáreas sea proporcionalmente mayor que el de aquellos con más de cinco hectáreas. Sin embargo, este resultado puede deberse al simple hecho de que el aumento en las transferencias de Procampo es mayor para el primer grupo de hogares.

Para validar si el nuevo esquema de cuota diferenciada es efectivamente menos regresivo, el escenario final evalúa los efectos de aumentar exógenamente las transferencias de Procampo en $100 \mathrm{mdp}$ una vez que la economía rural se ha ajustado al esquema de cuota diferenciada. Los 100 mdp son asignados conforme a la nueva participación relativa de cada 
grupo de hogares en las transferencias totales de Procampo (cuadro 7 , columna 4).

Los resultados de esta política expost se muestran en la columna 3 del cuadro 8. El aumento en el ingreso de los hogares productores propietarios de entre dos y cinco hectáreas es proporcionalmente mayor que el de los de más de cinco hectáreas. Sin embargo, el aumento en el ingreso de los hogares productores dueños de menos de dos hectáreas no es proporcionalmente mayor que el de los demás.

\section{Cuadro 7}

\section{Distribución de las transferencias de Procampo en el sureste mexicano}

\begin{tabular}{|c|c|c|c|c|c|c|c|c|}
\hline \multirow[t]{2}{*}{$\begin{array}{l}\text { Grupo de } \\
\text { hogares }\end{array}$} & \multicolumn{2}{|c|}{$\begin{array}{l}\text { 1) Distribución } \\
\text { inicial }\end{array}$} & \multicolumn{2}{|c|}{$\begin{array}{l}\text { 2) Aumento } \\
\text { exógeno de } 100 \\
\text { mdp ex ante }\end{array}$} & \multicolumn{2}{|c|}{$\begin{array}{l}\text { 3) Cambio a cuota } \\
\text { diferenciada }\end{array}$} & \multicolumn{2}{|c|}{$\begin{array}{l}\text { 4) Aumento } \\
\text { exógeno de } 100 \\
\text { mdp ex post }\end{array}$} \\
\hline & $\begin{array}{l}\text { Monto } \\
(m d p)\end{array}$ & $\%$ & $\begin{array}{l}\text { Monto } \\
(m d p)\end{array}$ & $\%$ & $\begin{array}{l}\text { Monto } \\
(m d p)\end{array}$ & $\%$ & $\begin{array}{l}\text { Monto } \\
(m d p)\end{array}$ & $\%$ \\
\hline $\mathrm{PP}<2$ & 61.5 & 6.2 & 67.7 & 6.2 & 91.6 & 7.4 & 99.1 & 7.4 \\
\hline PP $2<$ ha $<5$ & 169.8 & 17.0 & 186.8 & 17.0 & 252.9 & 20.5 & 273.4 & 20.5 \\
\hline $\mathrm{PP}>5$ & 634.3 & 63.6 & 697.9 & 63.6 & 699.7 & 56.8 & 756.5 & 56.8 \\
\hline PNP $<2$ & 0.00 & 0.0 & 0.0 & 0.0 & 0.0 & 0.00 & 0.0 & 0.0 \\
\hline PNP $2<\mathrm{ha}<5$ & 113.7 & 11.4 & 125.1 & 11.4 & 169.3 & 13.7 & 183.0 & 13.7 \\
\hline $\mathrm{PNP}>5$ & 17.6 & 1.8 & 19.3 & 1.8 & 19.4 & 1.6 & 20.9 & 1.6 \\
\hline NP & 0.0 & 0.0 & 0.0 & 0.0 & 0.0 & 0.0 & 0.0 & 0.0 \\
\hline Total & 996.9 & 100.0 & $1,096.0$ & 100.0 & $1,232.9$ & 100.0 & $1,332.9$ & 100.0 \\
\hline
\end{tabular}

Fuente: cálculos propios a partir de la MCRS del sureste mexicano (Enhrum, 2003).

Nota: $\mathrm{PP}=$ productores propietarios, $\mathrm{PNP}=$ productores no propietarios, $\mathrm{NP}=$ no productores.

El resultado implica que el cambio al esquema de cuota diferenciada en la implementación del Procampo trajo consigo efectos menos regresivos para los hogares rurales del sureste mexicano pero únicamente para aquéllos con extensiones de entre dos y cinco hectáreas. Los pequeños productores propietarios de menos de dos hectáreas no se benefician más que los hogares con extensiones de terreno mayores.

Los efectos multiplicativos generados por el incremento exógeno de las transferencias de Procampo no inciden significativamente en el ingreso de los productores más pequeños. Un incremento exógeno en las transferencias de Procampo, bajo el esquema actual de cuota diferenciada, no generaría efectos progresivos para el caso particular de los hogares productores propietarios de menos de dos hectáreas. 


\section{Cuadro 8}

\section{Efectos en la economía rural de cambios exógenos en la implementación del Procampo}

\begin{tabular}{|c|c|c|c|c|c|c|}
\hline & \multicolumn{2}{|c|}{$\begin{array}{l}\text { 1) Aumento } \\
\text { exógeno de } 100 \\
\text { mdp ex ante }\end{array}$} & \multicolumn{2}{|c|}{$\begin{array}{c}\text { 2) Cambio a } \\
\text { cuota diferencia- } \\
d a\end{array}$} & \multicolumn{2}{|c|}{$\begin{array}{l}\text { 3) Aumento exógeno } \\
\text { de } 100 \mathrm{mdp} \text { ex post }\end{array}$} \\
\hline & $\begin{array}{l}\text { Millones } \\
\text { de pesos }\end{array}$ & $\%$ & $\begin{array}{l}\text { Millones } \\
\text { de pesos }\end{array}$ & $\%$ & $\begin{array}{l}\text { Millones } \\
\text { de pesos }\end{array}$ & $\%$ \\
\hline \multicolumn{7}{|l|}{ Actividades Productivas } \\
\hline Básicos & 23.3 & 0.55 & 55.7 & 1.3 & 23.4 & 0.55 \\
\hline Otros cultivos & 1.9 & 0.13 & 4.6 & 0.3 & 1.9 & 0.13 \\
\hline Ganadería & 9.1 & 0.35 & 20.2 & 0.8 & 9.0 & 0.34 \\
\hline Comercio y servicios & 43.2 & 0.36 & 97.9 & 0.8 & 42.9 & 0.36 \\
\hline Recursos naturales y pesca & 31.2 & 0.50 & 71.6 & 1.1 & 31.0 & 0.49 \\
\hline \multicolumn{7}{|l|}{ Factores: } \\
\hline Tierra & 0.6 & 0.44 & 1.3 & 1.0 & 0.5 & 0.44 \\
\hline Capital & 2.2 & 0.46 & 5.3 & 1.1 & 2.2 & 0.46 \\
\hline Trabajo asalariado & 4.2 & 0.35 & 10.1 & 0.8 & 4.2 & 0.35 \\
\hline Trabajo familiar & 64.4 & 0.42 & 148.2 & 1.0 & 64.1 & 0.41 \\
\hline \multicolumn{7}{|l|}{ Hogares*: } \\
\hline $\mathrm{PP}<2$ & 14.3 & 0.48 & 49.2 & 1.6 & 15.5 & 0.51 \\
\hline pP $2<\mathrm{ha}<5$ & 24.5 & 0.81 & 100.3 & 3.3 & 27.9 & 0.90 \\
\hline $\mathrm{PP}>5$ & 87.9 & 0.95 & 122.7 & 1.3 & 81.0 & 0.87 \\
\hline $\mathrm{PNP}<2$ & 5.3 & 0.30 & 12.6 & 0.7 & 5.3 & 0.30 \\
\hline PNP $2<\mathrm{ha}<5$ & 15.1 & 1.10 & 64.2 & 4.7 & 17.4 & 1.21 \\
\hline $\mathrm{PNP}>5$ & 3.1 & 0.67 & 4.8 & 1.1 & 2.9 & 0.62 \\
\hline NP & 31.1 & 0.30 & 72.4 & 0.7 & 31.0 & 0.30 \\
\hline
\end{tabular}

Fuente: cálculos propios a partir de la MCRs del sureste mexicano (Enhrum, 2003).

Nota: $\mathrm{PP}=$ productores propietarios, $\mathrm{PNP}=$ productores no propietarios, $\mathrm{NP}=$ no productores

Sin embargo, vale la pena resaltar que el incremento ex post en el ingreso de los hogares propietarios de menos de cinco hectáreas es mayor al incremento ex ante lo cual implica que el esquema de cuota diferenciada ha mejorado los efectos distributivos del Programa, aun tomando en cuenta los efectos multiplicadores generados tras su implementación.

\section{Conclusiones}

El modelo de multiplicadores basado en la estructura económica representada por una MCs captura la heterogeneidad en las actividades de 
producción, fuentes de ingreso y patrones de consumo de los hogares rurales y establece claramente la vinculación que existe entre los diversos sectores de la economía rural. En esta investigación se hizo uso de las ventajas provistas por la MCS y el modelo de multiplicadores para analizar los efectos derivados de cambios en la implementación del programa Procampo en el contexto de la economía rural del sureste mexicano.

Los resultados indican que un aumento en las transferencias del Procampo va más allá del simple aumento en los ingresos de los distintos grupos de hogares que reciben este apoyo: el ingreso de otros hogares, la producción de los sectores económicos y la demanda de factores productivos del sureste rural también aumentan. Sin embargo, los resultados del escenario que evalúa los efectos de un aumento de las transferencias del Procampo, bajo el esquema de cuota única vigente hasta el 2008, indican que el Procampo generó efectos regresivos para los hogares rurales del sureste mexicanos, ya que los más beneficiados fueron los que concentraron la mayor cantidad de los recursos del programa.

La introducción del esquema de cuota diferenciada de Procampo, vigente desde 2009, representó un cambio positivo en la implementación del programa. Al introducir este cambio en el contexto de la economía rural del sureste, representada en la MCs para el año 2002, se muestra que tal esquema genera efectos más progresivos respecto al previo y permite a los pequeños productores beneficiarse más de las transferencias y de sus efectos multiplicadores. Los productores con extensiones de terreno de entre dos y cinco hectáreas se benefician proporcionalmente más que aquellos con predios de mayor tamaño.

Sin embargo, los productores más pequeños, aquellos propietarios de menos de dos hectáreas no se benefician proporcionalmente más que los hogares con extensiones mayores debido a su falta de vinculación con el resto de la economía rural. La mayor parte de estos productores se dedican exclusivamente a la producción de cultivos básicos (en gran medida para autoconsumo), y no participan en las actividades que mejor absorben los efectos multiplicativos creados en la economía rural ante choques exógenos positivos. Lograr un efecto progresivo del programa Procampo en este grupo de hogares requeriría diferenciar aún más el monto de las transferencias e incrementar más aquellas dirigidas a los hogares con menos de dos hectáreas.

Dadas las restricciones presupuestarias que enfrenta el sector público en materia de subsidios y a la poca escala de producción que representa este grupo de productores, esta alternativa resulta hasta cierto punto implausible en el corto plazo. Sin embargo, una política orientada al incremento de la productividad de los productores más pequeños tendría un efecto directo en la reducción de la pobreza. 
El potencial para incrementar la productividad de los pequeños productores no ha sido explotado debido a que, de facto, se asume que su contribución es marginal en el agregado agropecuario (Unctad, 2013). Lo anterior depende por supuesto de que Procampo adopte un enfoque productivo ligado directamente a las decisiones de producción de los productores rurales.

El esquema de cuota diferenciada ha mejorado los efectos distributivos del programa. Ante un incremento exógeno de las transferencias de Procampo, el incremento proporcional en el ingreso de los hogares con hasta cinco hectáreas es mayor con el esquema de cuota diferenciada que con el esquema de cuota única. Si bien se requieren esfuerzos adicionales para eliminar por completo la regresividad del programa, el cambio en su implementación ha mejorado el papel que Procampo desempeña en la economía rural y, en particular, en el ingreso de los hogares, al menos para el caso del sureste mexicano.

Los resultados de esta investigación se podrían contrastar con los obtenidos a partir de enfoques diferentes, de equilibrio general o econométricos, para establecer con una mayor precisión el margen de los efectos finales de cambios exógenos. Esta investigación explora el caso particular de la región sureste de México y del programa Procampo, pero el análisis puede extenderse a otras regiones del país y al análisis de la implementación de cualquier política agrícola que tenga por objetivo la promoción del desarrollo rural.

\section{Bibliografía}

Adelman, Irma, Edward Taylor y Sthepen Vogel (1988), "Life in a mexican village: a sAm perspective", Journal of Development Studies, 25 (1), Routledge, London, pp. 5-24.

Adelman, Irma y Edward Taylor (1990), "Is structural adjustment with a human face possible? The case of Mexico", Journal of Development Studies, 26 (3), Routledge, London, pp. 387-407.

Adelman, Irma y Edward Taylor (1991), "Multisectorial models and structural adjustment: new evidence from Mexico", Journal of Development Studies, 28 (1), Routledge, London, pp. 154-163.

Cuecuecha, Alfredo y John Scott (2009), "The effect of agricultural subsidies on migration and agricultural employment", documento de trabajo no. 474, Centro de Investigación y Docencia Económicas, México. 
Defourny, Jacques y Erik Thorbecke (1984), "Structural path analysis and multiplier decomposition within a social accounting matrix framework", The Economic Journal, 94, Wiley, Oxford, pp. 111-136.

DOF (Diario Oficial de la Federación) (2002), "Secretaría de Agricultura, Ganadería, Desarrollo Rural, Pesca y Alimentación. Reglas de operación del Programa de Apoyos Directos al Campo (Procampo) para los ciclos agrícolas primavera-verano 2002 y otoño-invierno 2002-2003", Secretaría de Gobernación, 20 de febrero, México.

DOF (Diario Oficial de la Federación) (2009), "Secretaría de Agricultura, Ganadería, Desarrollo Rural, Pesca y Alimentación. Acuerdo por el que se modifican y adicionan diversas disposiciones a las Reglas de Operación del Programa de Apoyos Directos al Campo, denominado Procampo", Secretaría de Gobernación, 8 de abril, México.

Enhrum (Encuesta Nacional a Hogares Rurales de México) (2003), Programa de Estudios del Cambio Económico y la Sustentabilidad del Agro Mexicano, El Colegio de México A. C., <http://precesam. colmex.mx>, consultado el 16 de agosto de 2012.

García-Salazar, José Alberto, Rhonda Skaggs y Terry Crawford (2011), "Evaluation of the effects of Programa de Apoyos Directos al Campo (Procampo) on the market of maize in Mexico, 20052007", Economía, Sociedad y Territorio, 36 (11), El Colegio Mexiquense, A. C., Zinacantepec, pp. 487-512.

Holden, Stein, Edward Taylor y Sthepen Hampton (1999), "Structural adjustment and market imperfections: a stylized village economywide model with non-separable farm households", Environment and Development Economics, 4 (1), Cambridge University Press, Cambridge, pp. 69-87.

Khan, Haider y Erik Thorbecke (1989), "Macroeconomic effects of technology choice: multiplier and structural path analysis within a SAM framework", Journal of Policy Modeling, 11(1), Elsevier, New York, pp. 131-156.

Lewis, Blane y Erik Thorbecke (1992), "District-level economic linkages in Kenya: evidence based on a small regional social ac- 
counting matrix", World Development, 20 (6), Elsevier, New York, pp. 881-897.

Lorenzen Martiny y James Matthew (2012), "Evaluación del Programa de Apoyos Directos al Campo (Procampo)", en Alicia Márquez Murrieta (coord.), Espacios tatuados. Textos sobre el estudio de las regiones y los territorios, Instituto de Investigaciones Dr. Jose María Luis Mora, México, pp. 61-94.

Parikh, Alka y Erik Thorbecke (1996), "Impact of rural industrialization on village life and economy: a social accounting matrix approach", Economic Development and Cultural Change, 44 (2), University of Chicago Press, Chicago, pp. 351-377.

Pyatt, Graham y Jeffery Round (1979), "Accounting and fixed price multipliers in a social accounting matrix framework", The Economic Journal, 89, Wiley, Oxford, pp. 850-873.

Round, Jeffery (2003), "Social accounting matrices and sAM-based multipliers analysis", Francois Bourguignon y Luiz Awasu Pereira de Silva (eds.), Tool kit for evaluating the poverty and distributional impact of economic policies, World Bank, Washington, pp. 301-324.

Ruiz-Arranz, Marta, Benjamin Davis, Sudhanshu Handa, Marco Stampini y Paul Winters (2006), "Program conditionality and food security: the impact of Progresa and Procampo transfers in rural Mexico", EconomiA, Elsevier, 2 (7), Brasilia, pp. 249-278.

Sadoulet, Elisabeth, Alain de Janvry y Benjamin Davis (2001), "Cash transfer program with income multipliers: Procampo in Mexico", FCND discussion paper no. 99, International Food Policy Research Institute, Washington.

Sagarpa (Secretaría de Agricultura, Ganadería, Desarrollo Rural, Pesca y Alimentación) (2006), "El sector agroalimentario mexicano: evolución, retos y perspectivas", Revista Claridades Agropecuarias, 157, Sagarpa-Aserca, México, pp. 6-28.

Sagarpa (Secretaría de Agricultura, Ganadería, Desarrollo Rural, Pesca y Alimentación) (2011), "Región Sur-Sureste: vocación y desarrollo", Servicio de Información Agroalimentaria y Pesquera, México. 
Schwentesius-Rindermannet, Rita, Manuel Ángel Gómez-Cruz, Juan de Dios Trujillo y Pedro Durán-Ferman (2007), "Metaevaluación de tres evaluaciones oficiales de la Sagarpa del programa de pagos directos (Procampo) a la agricultura mexicana", Estudios Sociales, 30 (16), Coordinación de Desarrollo Regional del Centro de Investigación en Alimentación y Desarrollo, México, pp. 104-134.

Subramanian, Shankar y Elisabeth Sadoulet (1990), "The transmission of production fluctuations and technical change in a village economy: a social accounting matrix approach", Economic Development and Cultural Change, 39 (1), University of Chicago Press, Chicago, pp. 131-173.

Taylor, Edward y Antonio Yúnez-Naude (2002), "Farm/non-farm linkages and agricultural supply response in México: a village-wide modelling", en B. Davis, T. Reardon, K. Stamoulis y P. Winters (eds.), Promoting Farm/non-farm linkages for rural development: case studies from America and Latin America, Food and Agriculture Organization of the United Nations, Roma, pp. 11-59.

Taylor, Edward, George Dyer y Antonio Yúnez-Naude (2005), "Disaggregate rural economywide models for policy analysis", World Development, 33 (10), Elsevier, Nueva York, pp. 1671-1688.

Unctad (United Nations Conference on Trade and Development) (2013), México's agriculture development: perspectives and outlook, United Nations, Geneva-New York.

Yúnez-Naude, Antonio y Edward Taylor (1999), "Manual para la elaboración de matrices de contabilidad social con base en encuestas socioeconómicas aplicadas a pequeñas poblaciones rurales", documento de trabajo no. 14, Centro de Estudios Económicos de El Colegio de México A. C., México.

Yúnez-Naude, Antonio y Edward Taylor (2006), "The effects of NAFTA and domestic reforms in the agriculture of Mexico: predictions and facts", Region et Développement, 23, L'Harmattan, París, pp. 161-186. 


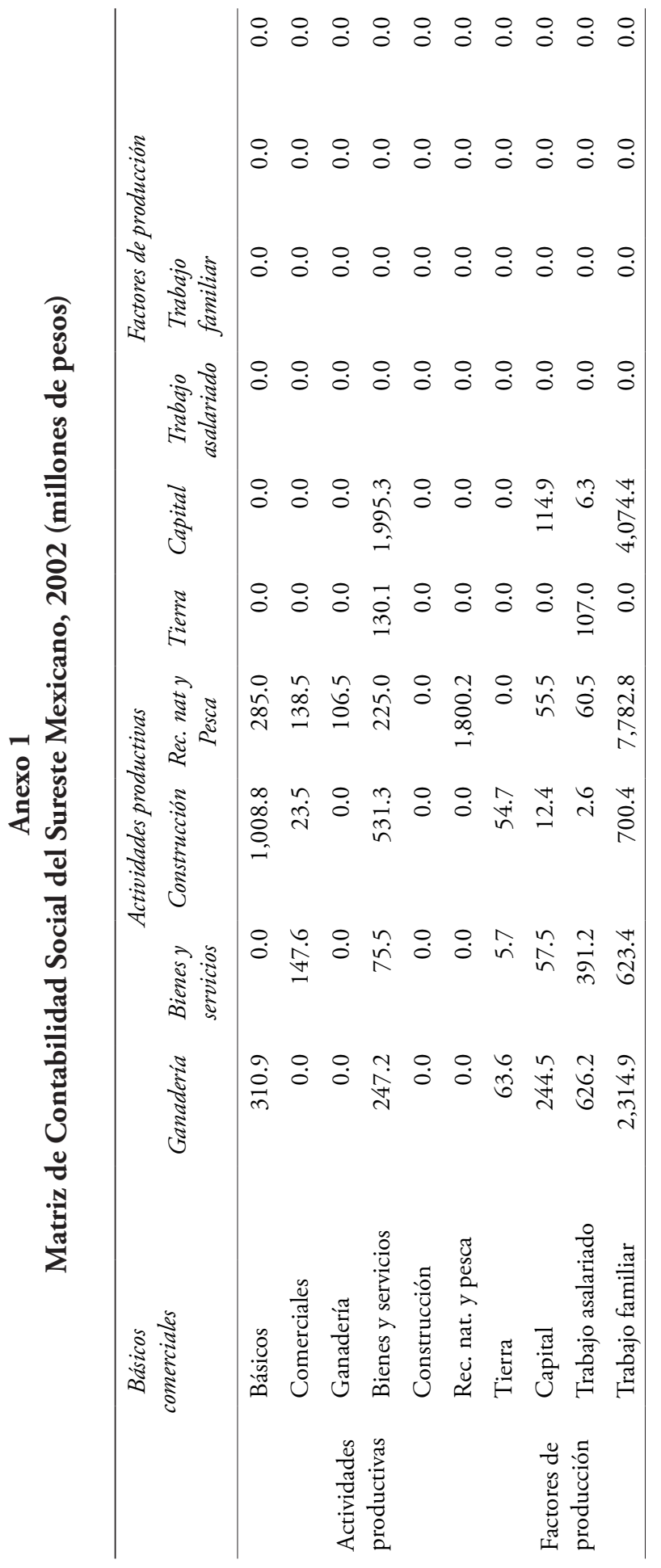




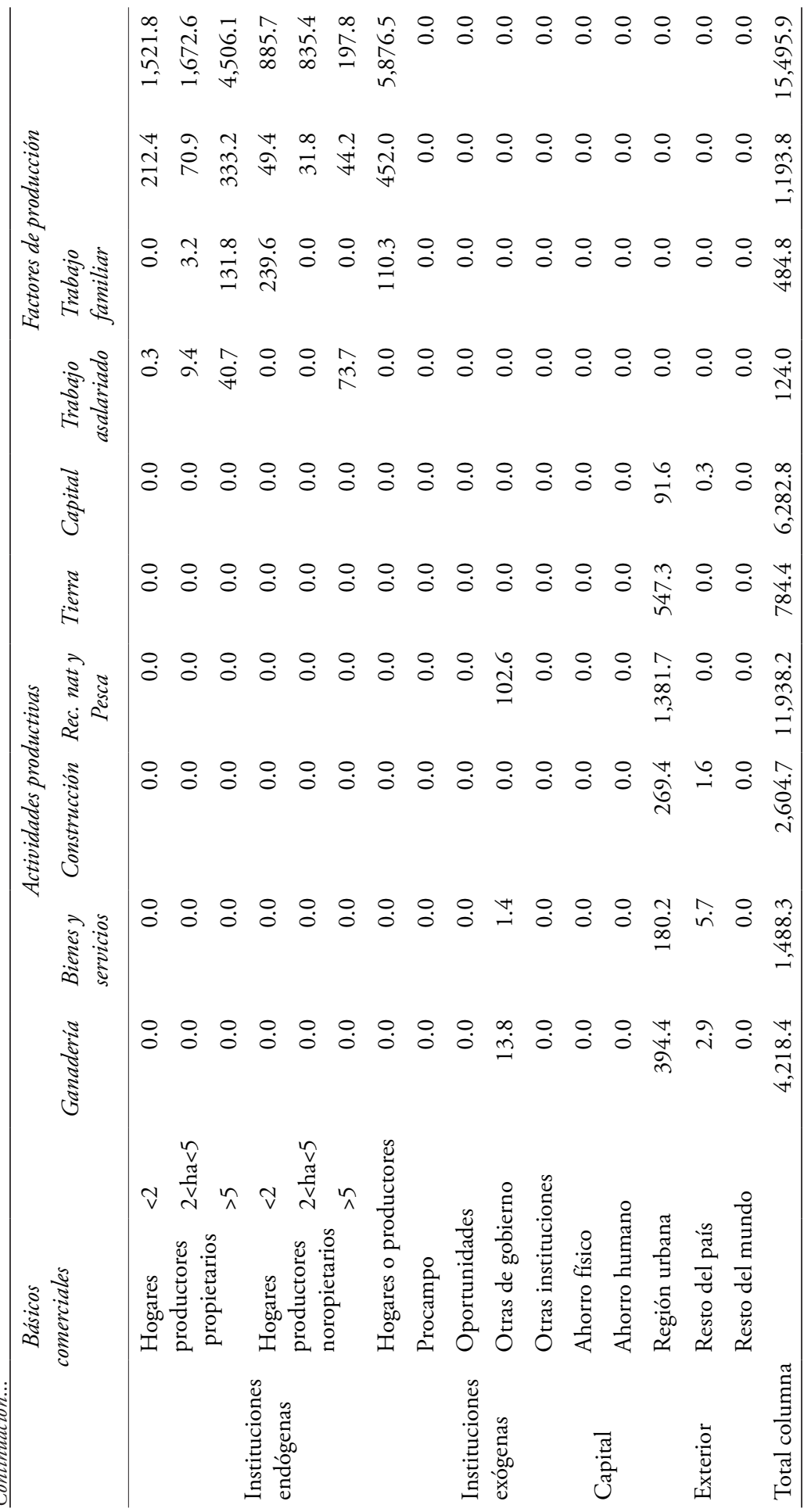




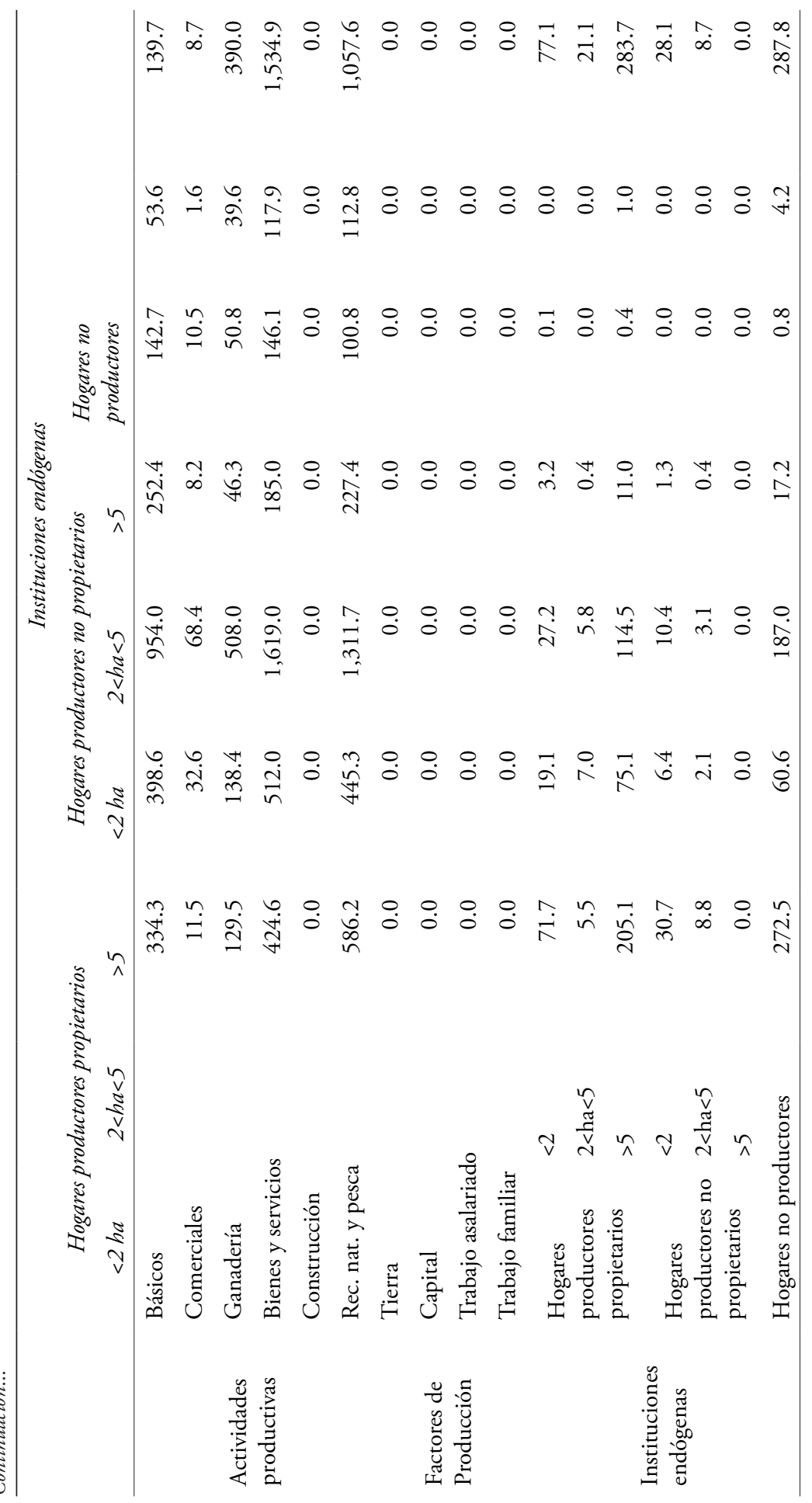




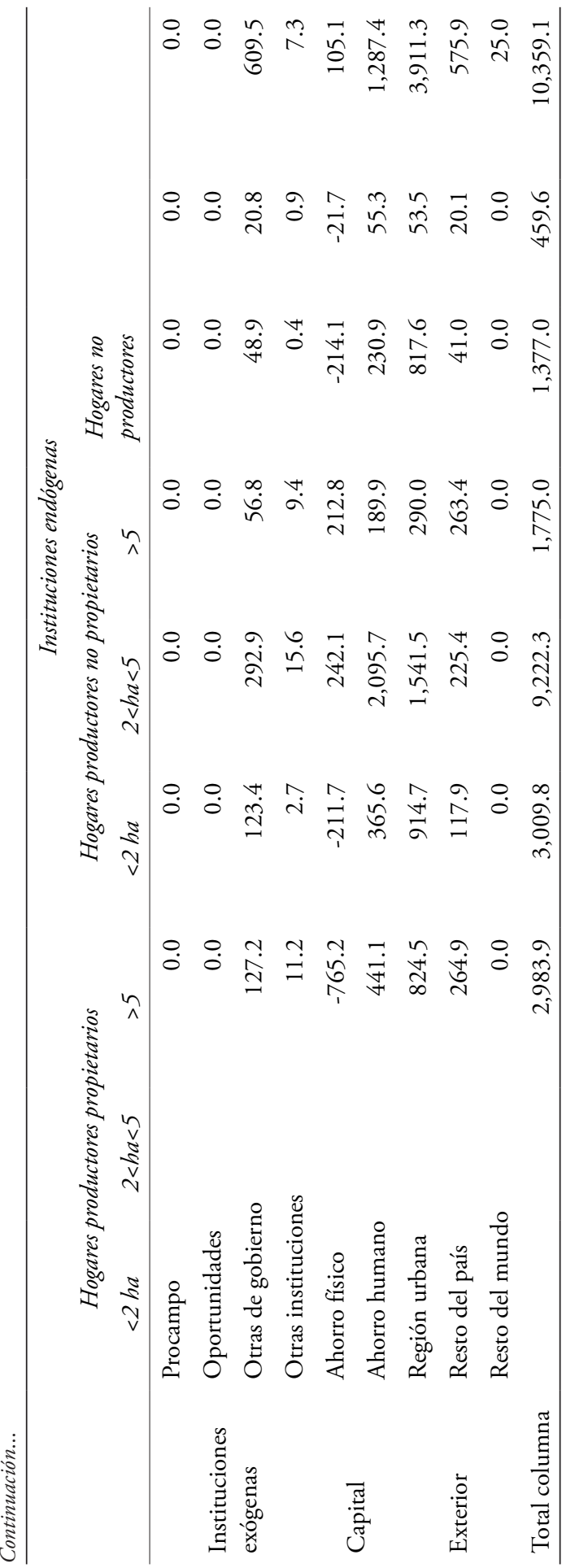




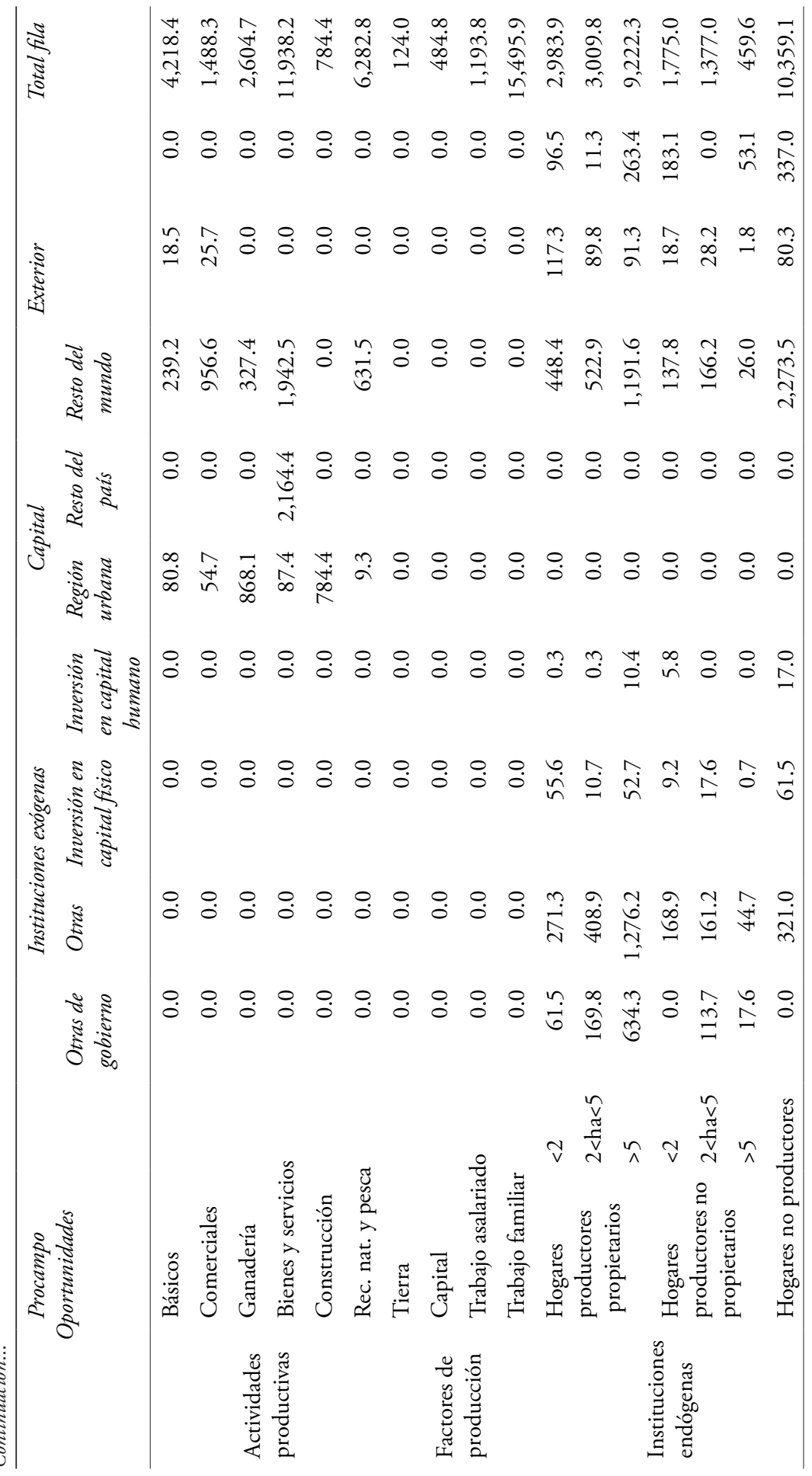




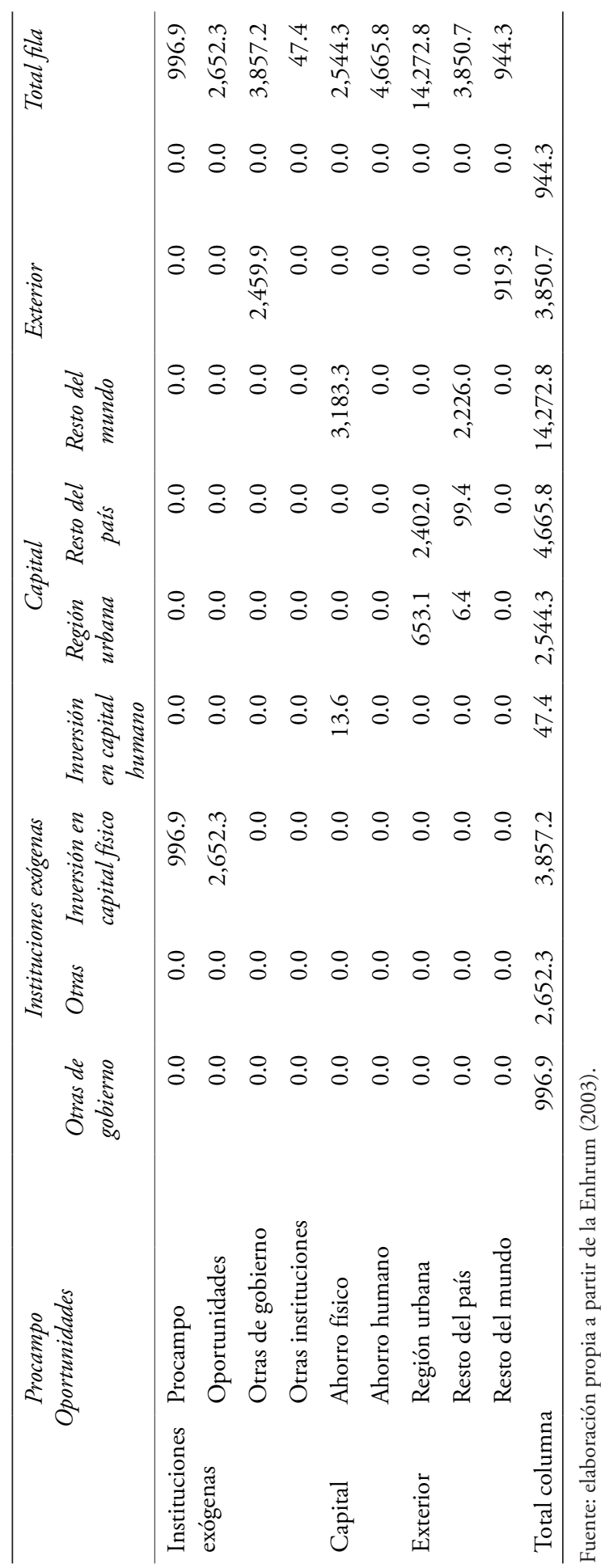


Recibido: 14 de septiembre de 2012.

Reenviado: 12 de julio de 2013. Aceptado: 4 de febrero de 2014.

Jesús Arellano-González. Mexicano. maestro en Economía por El Colegio de México A. C. Actualmente es funcionario público de la Financiera Nacional de Desarrollo Agropecuario, Rural, Forestal y Pesquero, Institución de Banca de Desarrollo sectorizada en la Secretaría de Hacienda y Crédito Público. Cuenta con una estancia de investigación acreditada por la Universidad de Yale. Su línea de investigación principal es la economía rural y se ha enfocado en temas como cambio climático, desarrollo económico, migración y modelos de equilibrio parcial y general. Entre sus publicaciones destacan, en coautoría, "A ricardian analysis of mexican farms", Environment and Development Economics, 15 (2), Cambridge University Press, Cambridge, pp. 153-171, (2010); en coautoría, "Cambios en el bienestar de 1990 a 2005: un estudio espacial para México", Estudios Económicos, 25 (2), El Colegio de México, México, pp. 363-406 (2010); en coautoría, "Migration and remittances effects on consumption of the poorest: the mexican case", Panorama Económico, 7 (14), Instituto Politécnico Nacional, México, pp 121-163 (2012). 